Research Article

\title{
Tire-Pavement Contact Stress Characteristics and Critical Slip Ratio at Multiple Working Conditions
}

\author{
Minrui Guo $\mathbb{D}^{1,2}$ and Xinglin Zhou ${ }^{1}$ \\ ${ }^{1}$ College of Automotive and Transportation Engineering, Wuhan University of Science and Technology, Wuhan 430000, China \\ ${ }^{2}$ College of Machinery and Energy Engineering, Huanghuai University, Zhumadian 463000, China
}

Correspondence should be addressed to Minrui Guo; 20131293@huanghuai.edu.cn

Received 24 March 2019; Revised 3 June 2019; Accepted 23 June 2019; Published 7 August 2019

Academic Editor: Charles C. Sorrell

Copyright (C) 2019 Minrui Guo and Xinglin Zhou. This is an open access article distributed under the Creative Commons Attribution License, which permits unrestricted use, distribution, and reproduction in any medium, provided the original work is properly cited.

The contact stress distribution of tire-pavement is generally assumed to be uniformly distributed in circles or rectangles in the pavement design. This simplification can solve some common engineering problems, but it neglects two factors including magnitude and direction of the contact stress. The main purpose of this paper is to analyze the contact stress distribution between the bus tire and the pavement under different driving conditions and pinpoint and compare the critical slip ratio during braking and acceleration. First, a tire-pavement simulated contact model is constructed by ABAQUS. Next, we compare, respectively, contact stresses in the vertical, longitudinal, and transverse directions at various rolling conditions and analyze the longitudinal forces at different slip ratios during braking and acceleration. It is observed that the magnitude, direction, and nonuniform distribution of contact stress are affected by the multiple working conditions while the bus is working. Meanwhile, in the braking and acceleration conditions, the longitudinal force grows rapidly as the slip ratio increases, and then grows slowly and at last decreases when the critical slip ratio is reached. However, the critical slip ratio at the time of braking differs from that at the time of acceleration, and the former is smaller than the latter.

\section{Introduction}

Tires are the important part of vehicles in different driving conditions (free rolling, acceleration, braking, and turning), which carry the load transfer between the vehicle and the ground, thereby creating various contact stresses and forces in the tire-pavement contact area [1-4]. Meanwhile, the slip ratio of braking and acceleration affects the stability and safety of vehicles [5].

The truck tire was modeled by Wang et al. [6] to simulate the contact stress under static and different driving conditions. They found that measured and predicted vertical contact stresses and tangential contact stresses are nonuniform. They also found that when the truck traveled at speeds of $10 \mathrm{~km} / \mathrm{h}$ or $30 \mathrm{~km} / \mathrm{h}$ under braking condition, the critical slip ratio at both speeds was equal to approximately $10 \%$, and the friction force reached its maximum [7]. But, in this study the critical slip ratio of the accelerated state was not analyzed. The shear stress distribution characteristics of racing tires were influenced by carcass deformation, and the contact stress of tire pavement under braking condition was analyzed in detail by Gruber and Sharp [8]. The established model could be used to evaluate the shape of the contact area of the tire and the rolling radius. In addition, the magnitude and distribution of the shear stress were significantly affected by the rolling radius and friction [9]. This study was meaningful in terms of research aspect. The three-dimensional stress distribution of heavy-duty truck tires under various rolling conditions was obtained, and it pointed out that the critical slip ratio was around $18 \%$, the braking force reached its maximum [10], whereas the critical slip rates for acceleration and braking state were not compared. A widebase tire was modeled by Hernandez and Al-Qadi [11] to predict contact stress. The longitudinal forces of the tire under different loads and inflation pressures were analyzed under different rolling conditions. It could be obtained from the above literature analysis that the contact stress characteristics of the truck tires, racing tires, heavy-duty truck tires, and wide-base tires were analyzed. However, the contact stress characteristics of the bus tires under multiple 
operating conditions and the different critical slip ratio during acceleration and braking conditions have not been studied.

There are many experimental instruments that can be used to test the contact stress and force between tire-pavement, such as pressure sensors, piezoelectric sensor arrays, ultrasonic waves, and pressure sensitive films [12-16]. However, these experimental instruments are expensive and take a long time with low efficiency. In addition, the accuracy and sensitivity of the experimental test depend on the number and accuracy of the sensor, the position and arrangement of the sensor, the rolling speed and driving conditions of the tire, the structure and use conditions of the tire, and the structure and friction coefficient of the road surface. During the course of the experiment, these factors may change at any time due to the interaction between the rolling tire and the road surface, which may lead to large experimental test errors.

Based on the above literature analysis, the main purpose of this paper is to develop a theoretical approach to simulate contact stress between the bus tire and pavement and explore the critical slip ratio during acceleration and braking stages under different conditions of the tire. This goal is achieved with a three-dimensional tire-pavement interaction model. With the help of large finite element analysis software ABAQUS, stress distribution is investigated in free rolling, acceleration, and cornering. The study compares, respectively, the vertical contact stress $\delta z$, longitudinal contact stress $\delta x$, and transverse contact stress $\delta y$ at free rolling, acceleration, and cornering conditions and analyzes the change in longitudinal force to pinpoint and compare the critical slip ratio during braking and acceleration.

\section{Materials and Methods}

In the following sections, we mainly discuss parameters' characteristics of rubber and tire materials. Also, the method of establishing a tire-pavement model is analyzed and studied. Before setting up a tire-pavement model, the selected tires must comply with national standards. According to the Chinese national standard GB/T29772016 , this paper selects the $275 / 70 \mathrm{R} 22.5$ radial tire, which is fitted to the bus.

2.1. Rubber Material. Due to the viscoelasticity and strong hyperelasticity of the rubber material, its stress-strain relationship shows obvious nonlinearity, which can be expressed by a polynomial model, and equation (1) is a common Mooney-Rivlin material model:

$$
U=C_{10}\left(I_{1}-3\right)+C_{01}\left(I_{2}-3\right)+\frac{1}{D_{1}}(J-1)^{2} .
$$

When $C_{01}=0$, equation (1) evolves into the Neo-Hookean material model as shown in the following equation:

$$
U=C_{10}\left(I_{1}-3\right)+\frac{1}{D_{1}}(J-1)^{2},
$$

where $U$ is the strain potential energy, $C_{10}$ and $C_{01}$ are the material constant, $I_{1}$ and $I_{2}$ are the invariant part of the deformation tensor, $J$ is the elastic volume ratio, and $D_{1}$ is the material parameter, indicating the compressibility of the material. Equation (2) could better simulate small strain and medium strain of the material, and it has good stability. Therefore, the Neo-Hookean model is used to simulate the hyperelasticity behavior, and the prony series is used to define its viscoelastic behavior. The Neo-Hookean model parameters and the prony series parameters from the uniaxial tensile test and dynamic mechanical analysis are provided by the tire manufacturer [17], as shown in Tables 1 and 2.

2.2. Materials of Bus Tire. Tire is a kind of complex composite material, which includes both nonlinear rubber and reinforcement in different directions. The reinforcement consists of steel-belt-1, steel-belt-2, and the radial ply, which are assumed to be linear elastic and are characterized following the uniaxial tensile test. In this test, the strain is measured by applying a tensile load. The elastic modulus can be calculated by stress-strain relationship. Six samples are tested for each material, and the average of the six moduli is used as input in the material model. Area per bar represents the cross-sectional area of each layer of rebar, and spacing indicates the spacing of the membrane units. The material parameters of the tire components, derived from the tire manufacturer, are shown in Table 3.

2.3. Establishing Tire-Pavement Model. Figure 1 shows meshes of the bus tire components for the modeled tire (275/ 70R22.5), including tread, sidewall, steel-belt-1, steel-belt-2, radial ply, and shoulder rubber. The tread has four longitudinal patterns, which divide tread into five longitudinal ribs. The static load radius of the tire is $479 \mathrm{~mm}$, and the section height is $193 \mathrm{~mm}$. The direction angle of steel-belt-1 is $20^{\circ}$, the direction angle of steel-belt- 2 is $-20^{\circ}$, orientation angle indicates the angle of steel-belt with respect to the circumferential direction, and radial ply is perpendicular to the circumferential direction of the tire. In the process of meshing, the denser the mesh, the higher the accuracy of the result. When the mesh is infinite, the calculated value is about the actual value, but the increase of the number of meshes will lead to the extension of the calculation time and the increase of the long disk space. Grid quality seriously affects the accuracy and difficulty of convergence, and good grid quality makes it easier to obtain accurate calculation results. Therefore, in the key parts of the key research, it should be ensured to divide the high-quality mesh. This paper focuses on the contact area of the tire ground, and the mesh of the part should be appropriately dense. In the secondary part of the structure, such as in the sidewall portion, the meshing can be sparse. Figure $1(\mathrm{~g})$ is a threedimensional model of full tire. When the tire of the bus is in contact with the road surface, the degree of the deformation of the tire is much larger than that of the road surface. It can be assumed that the road surface is a nondeformable flat surface to achieve better computational efficiency and stability, and this does not affect the accuracy of the stress analysis of the tire-pavement. The three-dimensional model 
TABLe 1: Neo-Hookean model parameters of the rubber material.

\begin{tabular}{lccc}
\hline Rubber material & $C_{10}$ & $C_{01}$ & $D_{1}$ \\
\hline Tread & $8.35 e 5$ & 0 & $2 e-8$ \\
Sidewall & $1.0 e 6$ & 0 & $5 e-6$ \\
\hline
\end{tabular}

TABle 2: Prony series parameters of the rubber material.

\begin{tabular}{cccc}
\hline$i$ & $g_{i}$ & $k_{i}$ & $\tau_{i}$ \\
\hline 1 & 0.303 & 0 & 0.102 \\
2 & 0.147 & 0 & 2.535 \\
3 & 0.037 & 0 & 20.977 \\
4 & 0.025 & 0 & 325.235 \\
\hline
\end{tabular}

of the generated tire-pavement is shown in Figure 1(h). The assumption of nondeformable surface has been applied successfully in previous research to study the contact stress at the tire-pavement interface [1, 18], while the assumption of a rigid wheel on soft soil is usually used in the field of terramechanics [19].

The tire-pavement-related parameters are the basis and premise of the analysis process, facilitating tire-pavement interaction analysis.

(1) Slip ratio $S_{\mathrm{a}}$ (equation (3)) is defined as the ratio of the tire sliding component to the free rolling in the accelerated condition [11], and it is calculated by

$$
S_{\mathrm{a}}=\left(1-\frac{v}{r w}\right) \times 100 \% \text {. }
$$

When the tire is at the free rolling condition, the relation between longitudinal translation speed and angular velocity is as follows:

$$
v=w r
$$

where $r$ is the rolling radius of the tire, $w$ is the angular velocity of the tire rolling, and $v$ is the longitudinal translation speed of the tire center.

(2) Slip ratio $S_{\mathrm{b}}$ (equation (5)) is defined as the ratio of the sliding component of the tire at the time of braking [11], and it is calculated by

$$
S_{\mathrm{b}}=\left(1-\frac{v}{r w}\right) \times 100 \% \text {. }
$$

(3) The frictional force $F$ (equation (6)) describes the maximum longitudinal force on the tire, when the slip ratio reaches the critical value, and the relation between friction force and normal force is as follows:

$$
F=\mu N \text {, }
$$

where $\mu$ is the friction coefficient of the road surface and $N$ is the normal force between the tire and pavement $(\mathrm{kN})$.

The friction model for the exponential decay function [20] has been examined by using proper numerical implementation [21], as follows:

$$
\mu=\mu_{\mathrm{k}}+\left(\mu_{\mathrm{s}}-\mu_{\mathrm{k}}\right) e^{-\alpha \cdot s},
$$

where $\mu_{\mathrm{k}}$ is the kinetic coefficient at the highest sliding speed, $\mu_{\mathrm{s}}$ is the static coefficient at zero sliding speed, $\alpha$ is the exponential decay coefficient, and $s$ is the sliding velocity. The static coefficient is defined as 0.6 , the kinetic coefficient is 0.5 , and $\alpha$ is selected as 0.05 .

(4) Critical slip ratio is defined as the slip ratio corresponding to the maximum longitudinal force when the bus is in the braking or the driving state.

2.4. Validation of the Three-Dimensional Model of TirePavement. The three nonlinear characteristics of material nonlinearity, geometric nonlinearity, and contact nonlinearity significantly affect the accuracy and computational efficiency of the dynamic analysis of the tire-pavement. Therefore, it is necessary to carry out experimental tests on the static contact between the tire and the road surface to ensure that the established $3 \mathrm{D}$ model is effective and accurate. It can be seen from Figure 2(b) that when the tire has a certain tire pressure, the maximum strain appears at a position close to the rim restraint, but the deformation value along the rim is 0 , and a large deformation occurs near the sidewall of the rim. Figure 2(c) shows a deformation nephogram along the tread. It can be noted that the deformation in 1 direction (U1) occurs primarily at the junction of the tread and the shoulder. Figure 2(d) shows a deformation nephogram along the sidewall, and it can be noted that the deformation in 2 orientation (U2) along the sidewall side occurs mainly at the sidewall. Therefore, as can be seen from Figures 2(b)-2(d), when the tire is subjected to a certain load, the main deformation part is on the sidewall of the tire. The results obtained are consistent with the literature [17]. This is expected and is in line with the actual situation.

The normal pressure distribution of the contact and the deformation in the normal direction (U3) when a certain load is applied to the tire are shown in Figures 2(e) and 2(f), respectively; it can be seen that the stress concentration mainly appears in the longitudinal ribs of the contact area, rather than appear in the groove. Comparison of Figures 2(e) and $2(\mathrm{f})$ shows that the positions with larger stress values have larger normal deformation.

The tire model can be calibrated by tire load-deflection curves. The error of predicted load-deflection curves and measured data should be within a reasonable range. Figure 3 shows the comparison of the predicted load-deformation data with the measured data at different inflation pressures ( $400 \mathrm{kpa}$ and $800 \mathrm{kpa}$ ) of the tire. It can be seen that the predicted results seem to be very close to the results of the experiments, and the predicted data is in agreement with the measured data with $5.62 \%$ error.

\section{Contact Stress and Critical Slip Ratio at Multiple Working Conditions}

3.1. Simulation Condition Design. When the $275 / 70 \mathrm{R} 22.5$ radial tire is fitted to the bus, with 10 tires, the total mass of the 
TABLE 3: Material parameter characteristics of each component of the tire.

\begin{tabular}{lcccccc}
\hline Tyre components & Young's modulus $(\mathrm{Pa})$ & Poisson's ratio & Density $\left(\mathrm{kg} / \mathrm{m}^{3}\right)$ & Area per bar $\left(\mathrm{m}^{2}\right)$ & Spacing $(\mathrm{m})$ & Orientation angle $\left(^{\circ}\right)$ \\
\hline Tread & $4 e 6$ & 0.49 & 1100 & - & - & - \\
Sidewall & $5 e 5$ & 0.49 & 1100 & - & - & - \\
Shoulder & $8 e 6$ & 0.49 & 1100 & - & - & - \\
Steel-belt-1 & & 0.30 & 5900 & $2.1 e-7$ & $1.2 e-3$ & -20 \\
Steel-belt-2 & From tests & 0.30 & 5900 & $2.1 e-7$ & $1.2 e-3$ & -20 \\
Radial ply & & 0.30 & 1500 & $4.2 e-7$ & $1 e-3$ \\
\hline
\end{tabular}

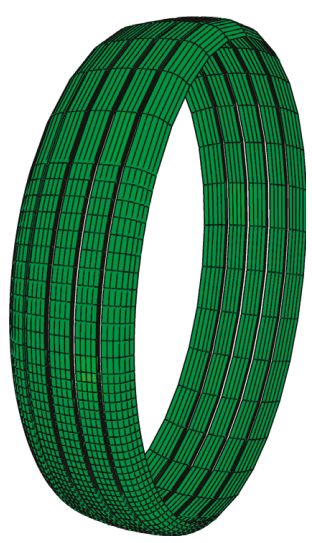

(a)

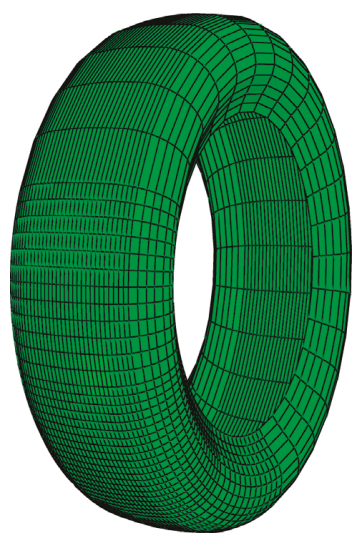

(e)

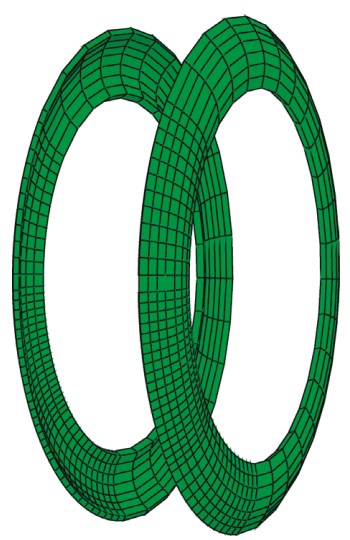

(b)

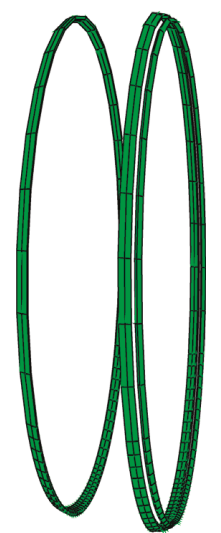

(f)

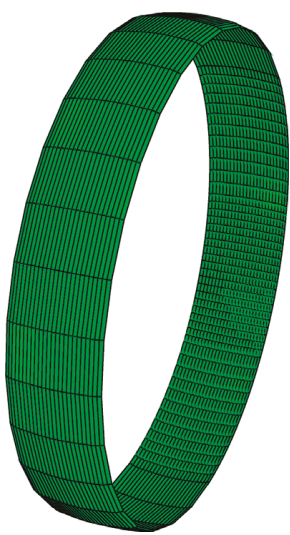

(c)

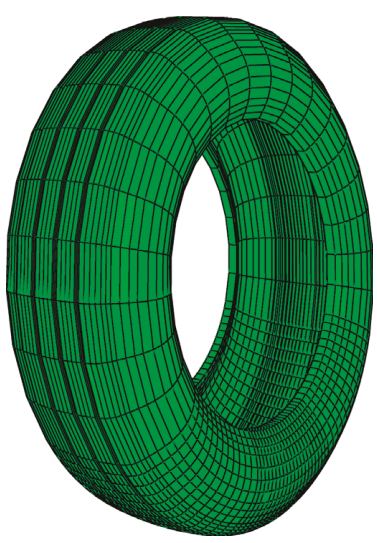

(g)

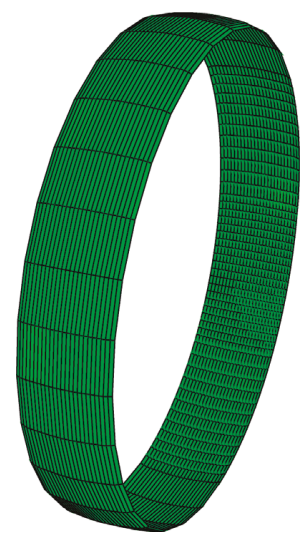

(d)

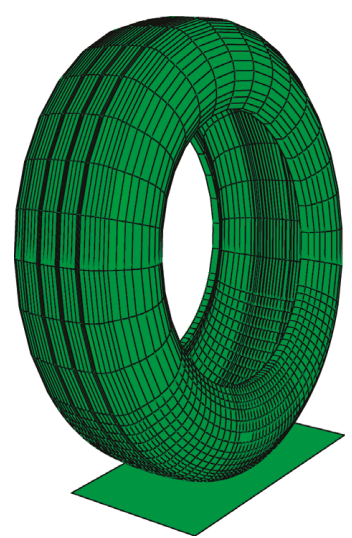

(h)

Figure 1: Meshes of bus tire components. (a) Tread. (b) Sidewall. (c) Steel-belt-1. (d) Steel-belt-2. (e) Radial ply. (f) Shoulder. (g) Full tire. (h) The tire-pavement contact.

bus is 22 tons, and the load of each tire is $\mathrm{N} 1=22 \mathrm{kN}$. According to the Chinese national standard GB/T2977-2016, the maximum load of the tire is $\mathrm{N} 3=30 \mathrm{kN}$, and $\mathrm{N} 2=26 \mathrm{kN}$ is the average value of $\mathrm{N} 1$ and $\mathrm{N} 3$. In addition, the standard tire pressure of the tire is $P 2=830 \mathrm{kPa}$, and $P 3=980 \mathrm{kPa}$ is the maximum tire pressure defined by the bus. $P 1=730 \mathrm{kPa}$ is the minimum tire pressure allowed in the tire specification. $v=15 \mathrm{~km} / \mathrm{h}$ is the common driving speed of the bus entering and leaving the bus station.

3.2. Tire-Pavement Contact Stress Analysis at Free Rolling Conditions. A typical working condition $(N=22 \mathrm{kN}$, $P=830 \mathrm{kPa}, v=15 \mathrm{~km} / \mathrm{h}$ ) is selected as the initial condition of the simulation, and the results are analyzed and compared. Figure 4 depicts the comparison of contact stresses in three directions at free rolling conditions. We can see the stress of each rib of the tire along the longitudinal contact length, as well as the specific location of the maximum contact stress. The maximum vertical stress occurs in the central rib of the tire, and the distribution of the vertical stress is basically symmetrical with respect to the imprinting center, because at this time the tire does not suffer from side deviation, side slip, or side inclination. The maximum longitudinal contact stress also occurs in the central rib, and the positive maximum and negative maximum longitudinal stresses are approximately equal, because the resultant longitudinal force is close to 0 , though not 0 , when the tire is rolling freely. However, the maximum transverse stress occurs in the intermediate rib of the tire, and the maximum lateral stress value is greater than the maximum longitudinal stress value, because the lateral stress is affected by the lateral 


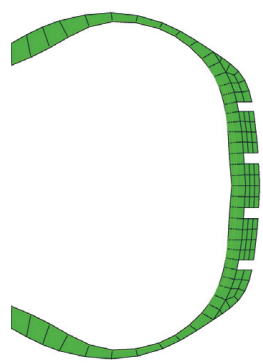

(a)

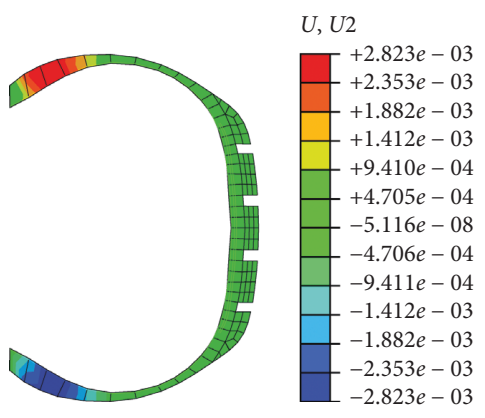

(d)

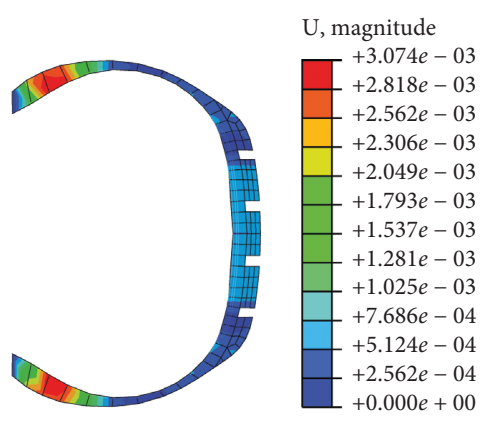

(b)

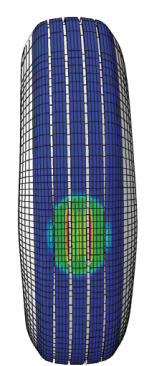

CPRESS

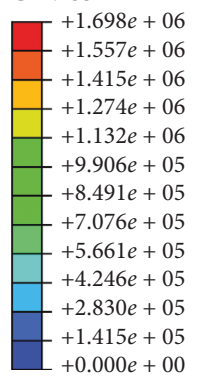

(e)

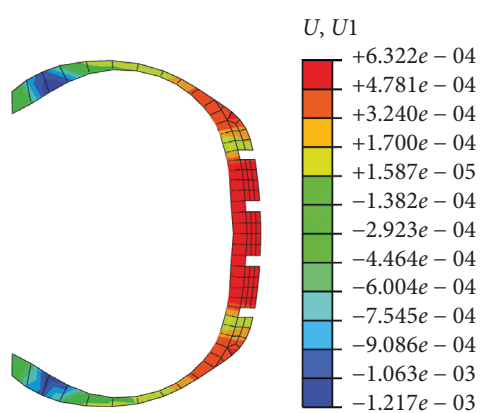

(c)

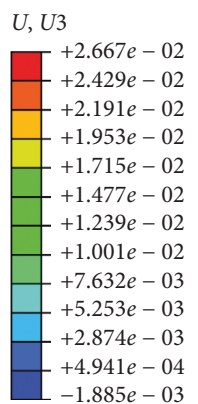

(f)

FIgURE 2: Stress and strain nephogram of the tire-pavement contact model. (a) The two-dimensional cross-section mesh of tire. (b) Displacement nephogram of the inflated tire rubber materials. (c) Displacement nephogram of $U 1$ along the tread. (d) Displacement nephogram of $U 2$ along the sidewall. (e) Pressure distribution of the tire contact region. (f) Displacement nephogram of U3 of the tire contact region.

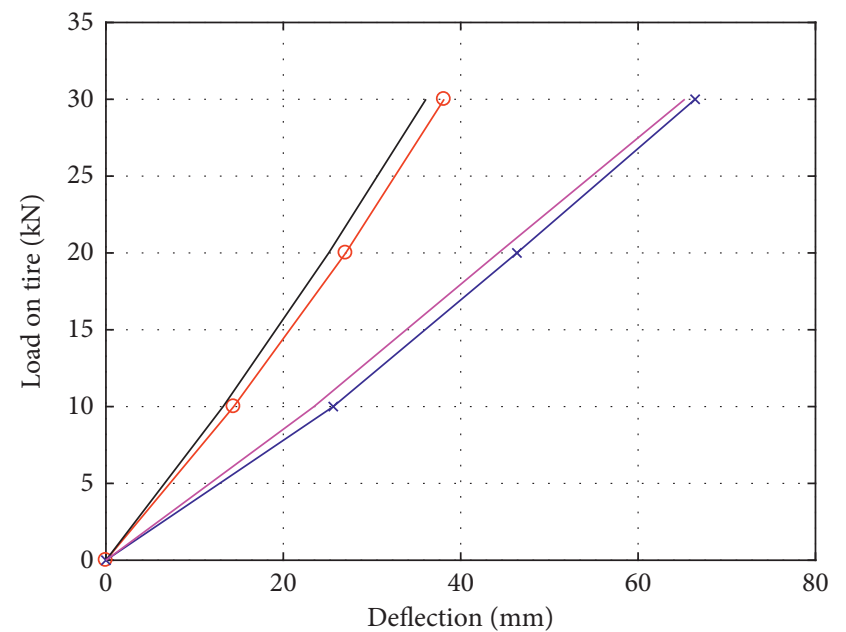

$\leftarrow$ Predicted data at $800 \mathrm{kPa} \rightarrow$ Predicted data at $400 \mathrm{kPa}$ — Measured data at $800 \mathrm{kPa}$ — Measured data at $400 \mathrm{kPa}$

FIGURE 3: Comparison of the predicted load-deformation data with the measured data.

displacement of the tread. In addition, since the tire load transmits through the sidewall, the lateral stress is inconsistent with respect to the front and back of the imprint center, and the maximum value of the positive direction is greater than the maximum value of the negative direction. The change trend of contact stresses is similar to the measured result of Pottinger [22]. It further explains that the simulation model is correct and reliable.

\subsection{Tire-Pavement Contact Stress Analysis at Full Acceleration} Conditions. Figure 5 shows comparison of contact stresses in three directions at full acceleration conditions. Compared to the free rolling condition, $\delta z$ changes very little, but $\delta y$ is reduced dramatically and even negligible. Meanwhile, the size, direction, and distribution of $\delta x$ have greatly changed. Because when the bus accelerates, it needs a large driving force, the contact displacement of the tire will be more restricted, and the size of $\delta x$ will be greatly increased. The direction of $\delta x$ in Figure 5(b) is negative, mainly because the power output of the engine is transmitted to the tire under acceleration conditions, and the ground exerts a forward driving force on the tire, so the ground is subjected to the rearward force of the tire. This is the opposite of the direction in which the tires advance. The stress distribution of the center rib is extremely similar with the research findings of Hernandez and Al-Qadi [11]. The study elaborated the change of contact stress of the center rib in different working conditions. In this paper, we analyze the stress characteristic of the intermediate rib and the edge rib as well as the center tire.

\subsection{Tire-Pavement Contact Stress Analysis at Cornering} Conditions. Slip angle is an important factor affecting the lateral force of a tire, which is defined as the angle between the tire turning plane and the motion direction of the center of the tire, and the clockwise direction is positive.

Figure 6 illustrates the comparison of contact stresses in three directions at cornering conditions $(v=15 \mathrm{~km} / \mathrm{h}$, slip angle $=3^{\circ}$ ). Both $\delta z \max$ and $\delta y \max$ are in the intermediate rib, while $\delta x \max$ is still in the center rib, but its value is small. 


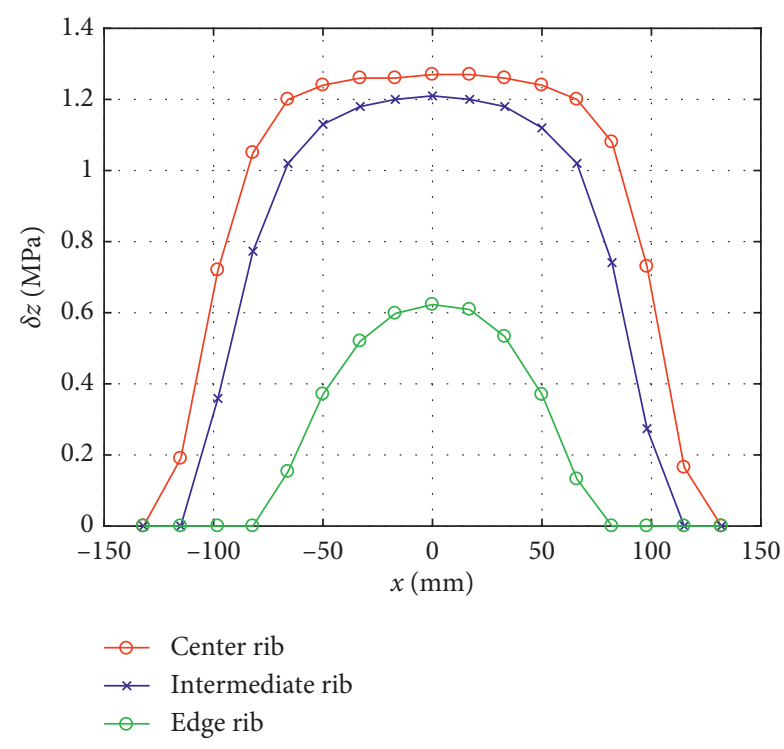

(a)

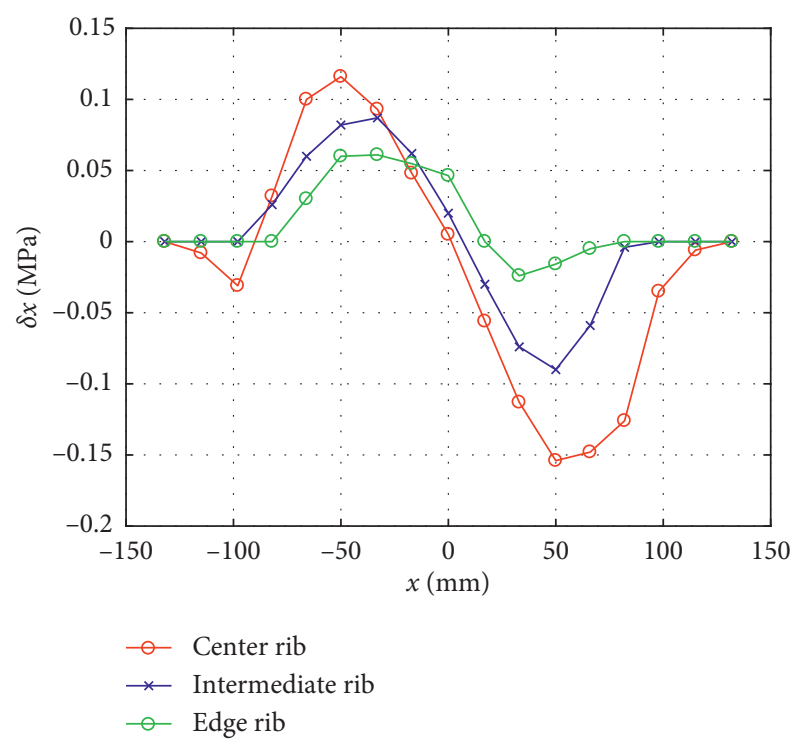

(b)

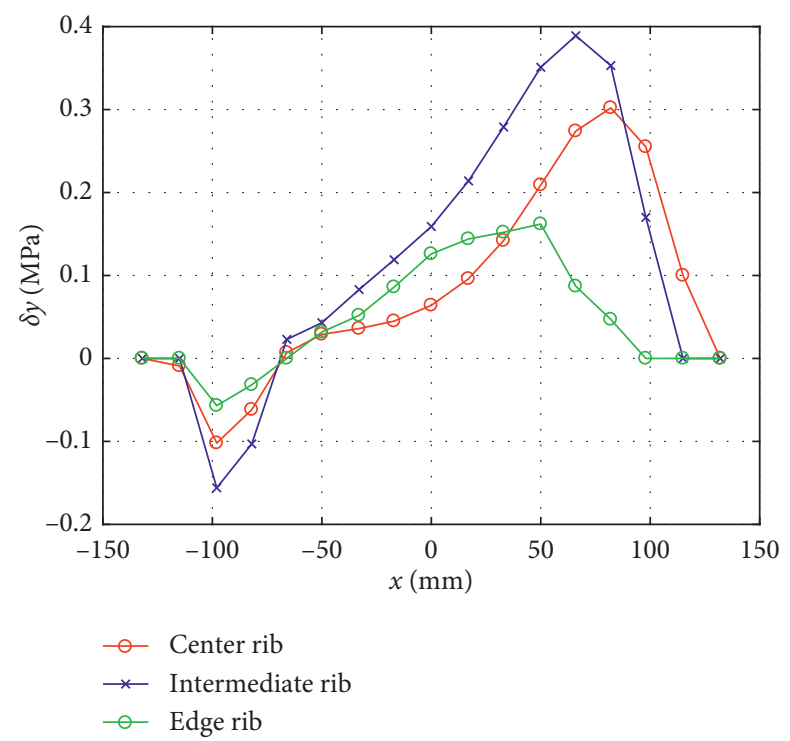

(c)

Figure 4: Comparison of contact stresses in (a) vertical, (b) longitudinal, and (c) transverse directions at free rolling conditions.

Compared with free rolling, $\delta z$ and $\delta y$ increase correspondingly in each rib of the tire, and the front and rear asymmetry of the tire grounding mark is mainly because the center of gravity of the tire moves in this direction when the bus turns in a certain direction. Furthermore, tire pressure on the ground and the distribution of lateral force are uneven, and the contact stresses of center rib and intermediate rib can confirm the correctness of the analysis, as shown in Figures 6(a) and 6(c). Because the lateral force is much larger than the longitudinal force during cornering, the value of $\delta x$ is much smaller than $\delta y$ when the tire grounding area does not change significantly.

3.5. Critical Slip Ratio Analysis. Figure 7 plots ground reaction force at different angular velocities during the tire rolling phase, and the effects of nine conditions of tire load and inflation pressure on the ground reaction force are analyzed. The ground reaction force is used to indicate the longitudinal force of the tire in ABAQUS, the two being equal in magnitude and opposite in direction. During the progress of the bus, it includes braking, acceleration, and free rolling. Since the tire is subjected to the torque of zero and the slip ratio of zero during free rolling, the angular velocity of the tire at this time could be calculated to be $9.4 \mathrm{rad} / \mathrm{s}$. When the angular velocity is less than $9.4 \mathrm{rad} / \mathrm{s}, v>r w$, the bus is in the braking state, and the ground reaction force is positive, but the longitudinal force of the tire is actually negative. When the angular velocity is larger than $9.4 \mathrm{rad} / \mathrm{s}$, the bus is in an accelerated state, the ground reaction force is negative, but the longitudinal force of the tire is actually positive.

It can also be seen from Figure 7 that the ground reaction force is affected by the load of the tire in addition to the 


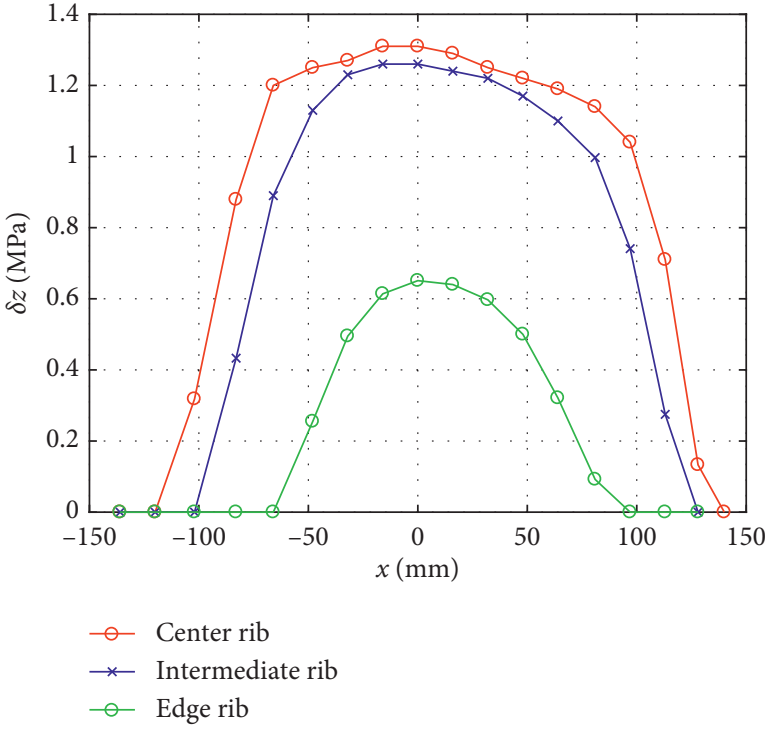

(a)

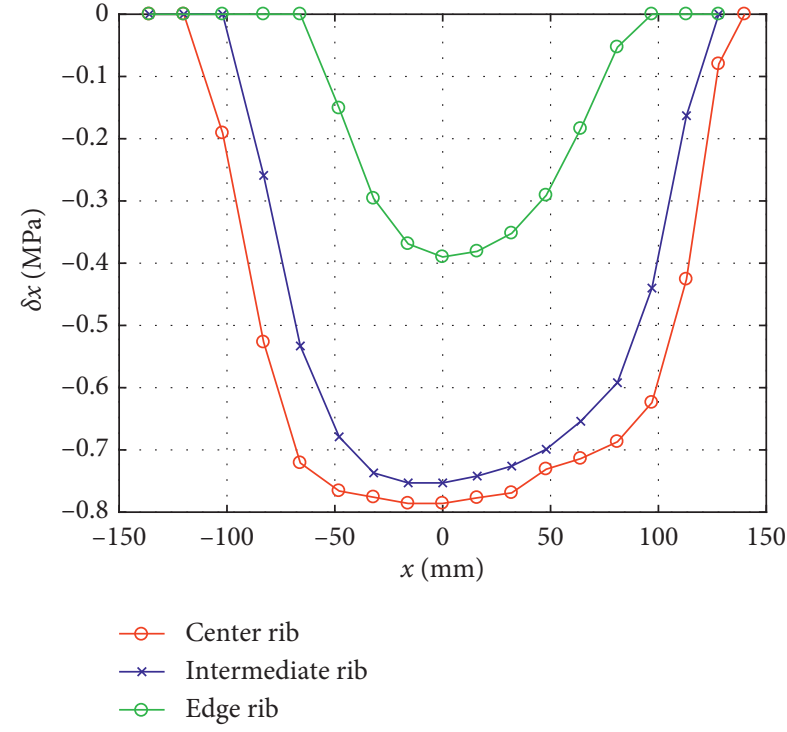

(b)

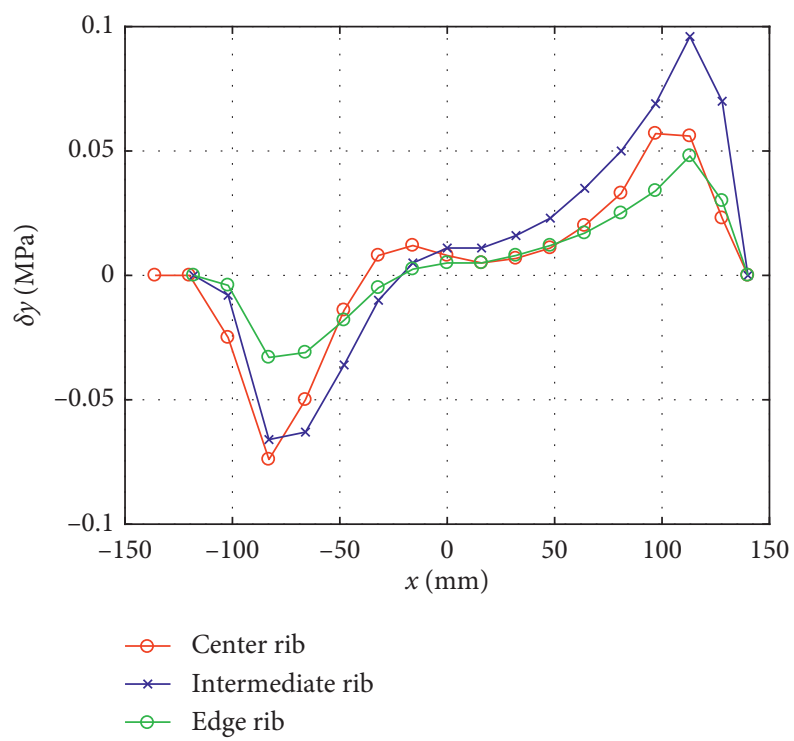

(c)

Figure 5: Comparison of contact stresses in (a) vertical, (b) longitudinal, and (c) transverse directions at full acceleration conditions.

angular velocity of the rolling of the tire, but has little to do with the inflation pressure of the tire. When the angular velocity of the tire is between $9 \mathrm{rad} / \mathrm{s}$ and $10 \mathrm{rad} / \mathrm{s}$, the ground reaction force changes drastically, while it is less than $9 \mathrm{rad} / \mathrm{s}$ and greater than $10 \mathrm{rad} / \mathrm{s}$, the ground reaction force does not change significantly. As the tire load becomes larger, the ground reaction force also becomes larger, but when it becomes larger to a certain extent, a maximum value occurs, which is mainly affected by the frictional force, because the bus is restricted by the ground attachment condition when it is normally driven. The longitudinal force of the tire does not exceed the friction of the ground.

In the driving dynamics of the vehicle, the longitudinal force is important, which is related to the steering stability of the whole vehicle. Figure 8 plots longitudinal force on the tire at different slip ratios in various loads and inflation pressures during braking. When the tire angular velocity is less than $9.4 \mathrm{rad} / \mathrm{s}$ at this stage, the bus is in the braking state. When the slip ratio increases, the longitudinal force of the tire becomes larger. When the slip ratio increases to $15.52 \%$ (critical slip ratio at braking), the longitudinal force of the tire reaches its maximum. When the slip ratio is less than $15.52 \%$, the contact area of the tire and the ground partially slips. When the slip ratio is larger than $15.52 \%$, the contact area between the tire and the ground all slips. At this time, the resultant longitudinal force $F x$ is mainly affected by the friction coefficient and the tire load.

In order to intuitively and clearly find the critical slip ratio under different conditions, nine combinations of different loads and inflation pressures are taken, as shown in Table 4. Being almost irrelevant to the tire inflation pressure, the longitudinal force is $F \times 1$ when the bus is in the working 


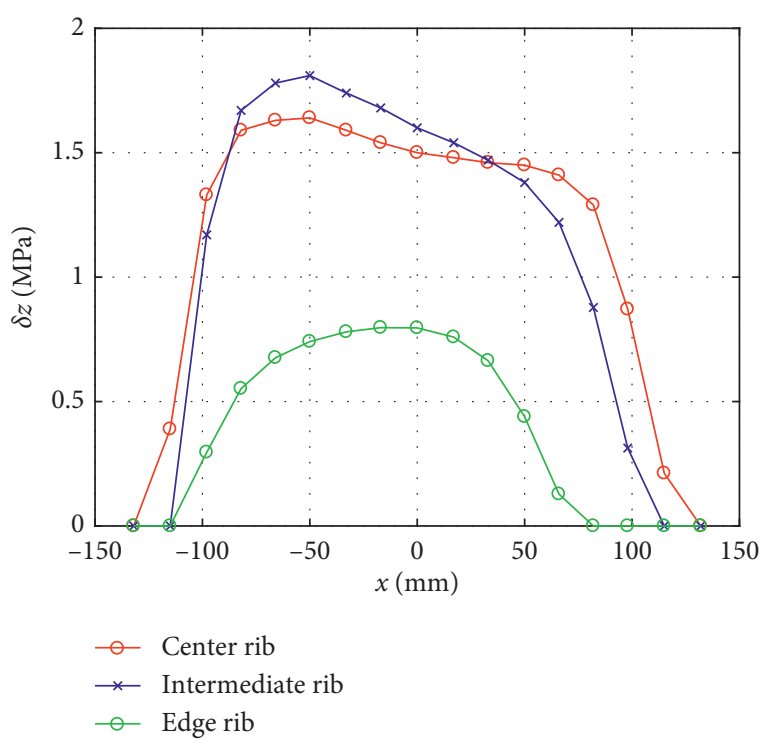

(a)

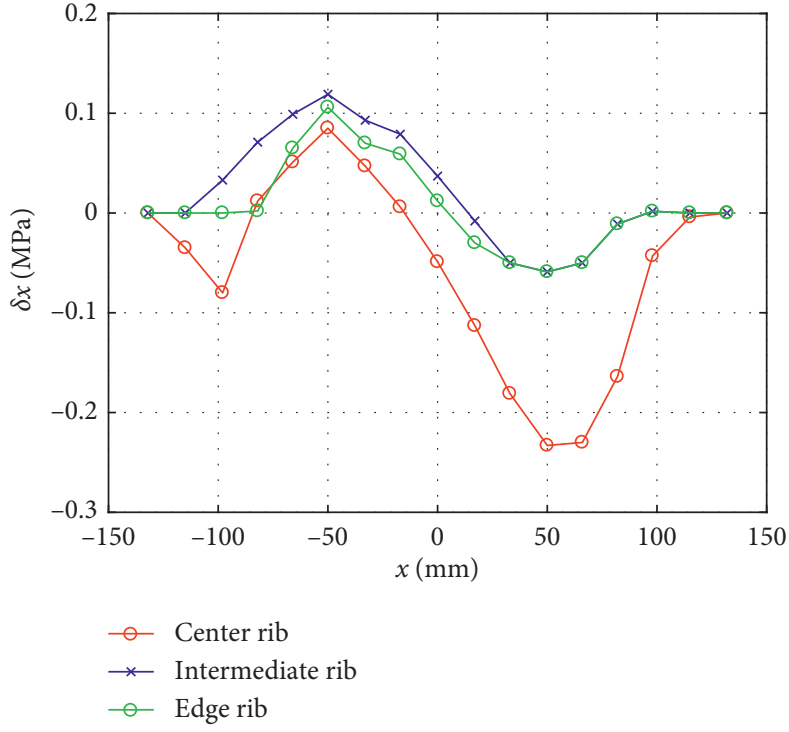

(b)

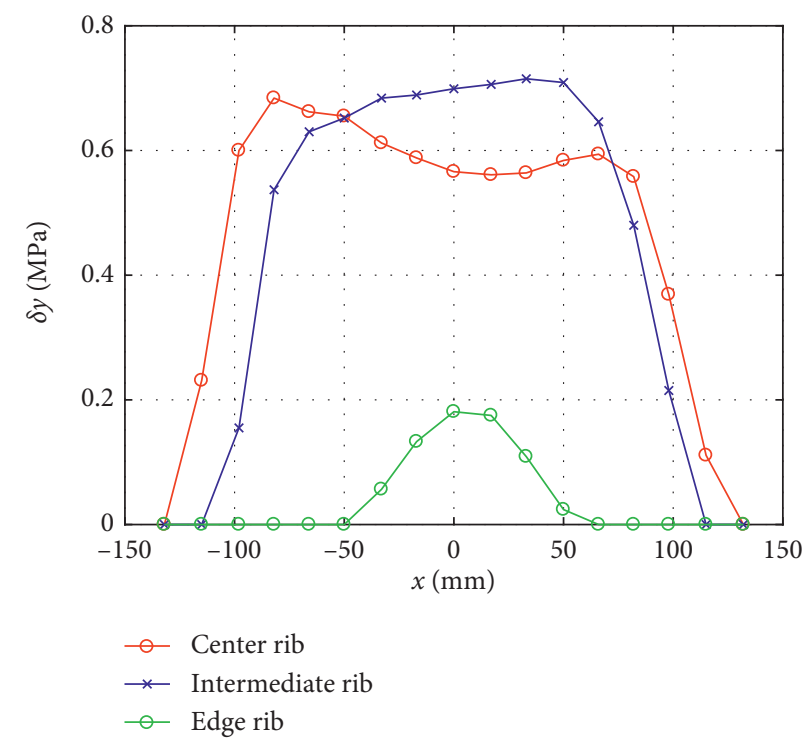

(c)

FIGURE 6: Comparison of contact stresses in (a) vertical, (b) longitudinal, and (c) transverse directions at cornering conditions.

conditions (N1P1, N1P2, and N1P3), and other combinations are similar.

Table 5 is specially designed to summarize the longitudinal force on the tire at some typical slip ratios during braking. According to the change of longitudinal force, the brake state can be divided into three stages with three different slip ratios. When the slip rate is less than $7.07 \%, F x$ is in the stage of rapid growth. In this stage, when the ground braking force appears, the tread in front of the tire which is about to contact the ground will be stretched and then elongated. $F x$ increases with the increase of rolling radius. When the slip ratio is greater than $7.07 \%$ and less than $15.52 \%, F x$ is in the stage of slow growth. This is because the increased speed of the grounding area of the tire becomes slow, the local relative slip of the grounding area occurs, and the increase of $F x$ is not obvious. When the slip ratio is greater than $15.52 \%$ and less than $100 \%, F x$ decreases as the slip ratio increases with exponential decay model, which is equal to the ground friction coefficient times the normal force; at this moment, the tire is in a state of complete braking and this state is dangerous driving condition, which may lead to the loss of control of the vehicle. In order to effectively and safely brake, drivers should make full use of the friction on the ground, making the slip rate close to but not more than $15.52 \%$.

Figure 9 presents longitudinal force on the tire at different slip ratios in various loads and inflation pressures during acceleration. Since the tire angular velocity is greater than $9.4 \mathrm{rad} / \mathrm{s}$ at this stage, the bus is in the accelerating state. As the slip ratio increases, the longitudinal force of the tire increases. When the slip ratio increases to $21.09 \%$ (critical slip ratio when accelerating), the 


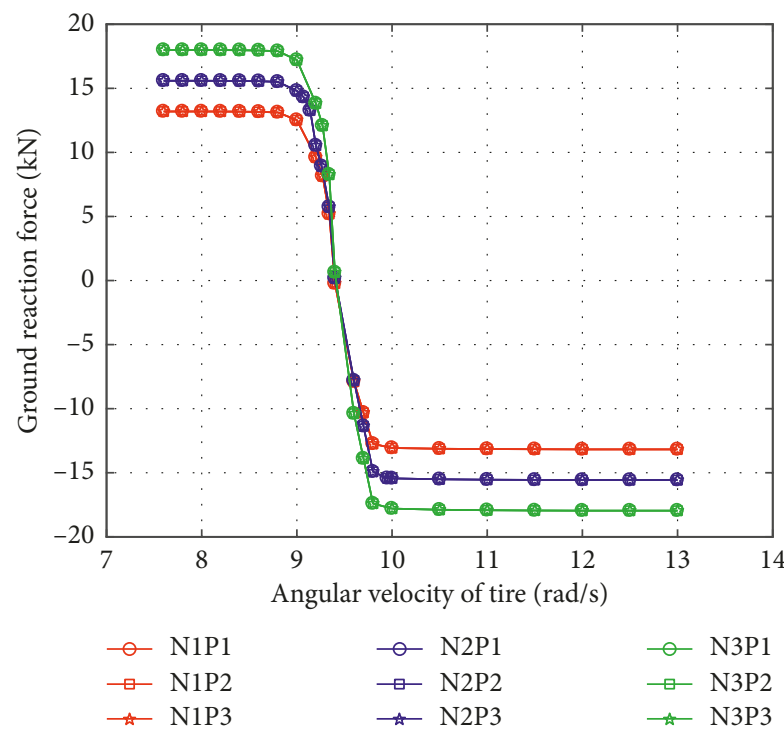

Figure 7: Ground reaction force at different angular velocities during the tire rolling phase.

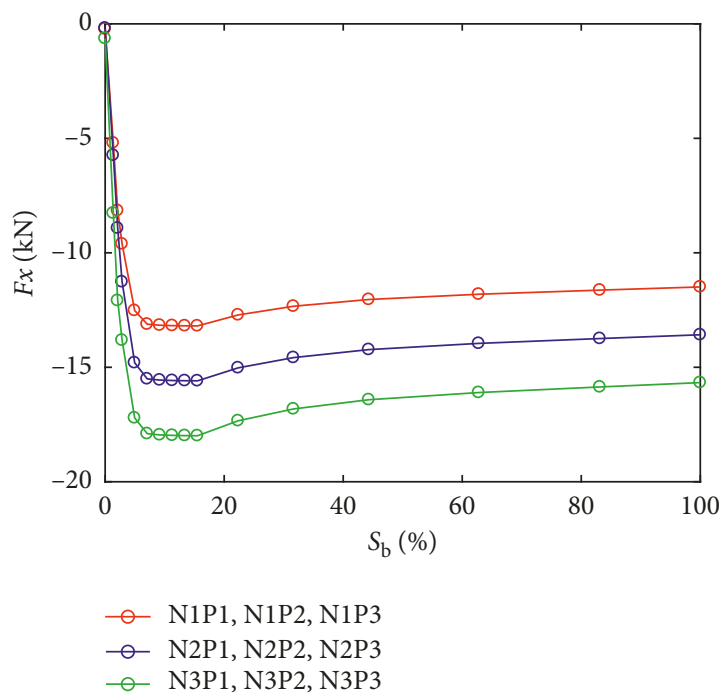

FIgURE 8: Longitudinal forces on the tire at different slip ratios under braking condition.

TABLE 4: Longitudinal forces corresponding to different combinations.

\begin{tabular}{|c|c|c|c|c|}
\hline \multirow{2}{*}{ Tire load $(\mathrm{kN})$} & \multicolumn{3}{|c|}{ Tire inflation pressure $(\mathrm{kPa})$} & \multirow{2}{*}{ Longitudinal force } \\
\hline & $P 1=730$ & $P 2=830$ & $P 3=980$ & \\
\hline $\mathrm{N} 1=22$ & N1P1 & N1P2 & N1P3 & $F x 1$ \\
\hline $\mathrm{N} 2=26$ & $\mathrm{~N} 2 \mathrm{P} 1$ & $\mathrm{~N} 2 \mathrm{P} 2$ & N2P3 & $F \times 2$ \\
\hline $\mathrm{N} 3=30$ & N3P1 & N3P2 & N3P3 & $F \times 3$ \\
\hline
\end{tabular}

TABLE 5: Longitudinal force on the tire at some typical slip ratios during braking.

\begin{tabular}{lccc}
\hline$S_{\mathrm{b}}(\%)$ & $F x 1(\mathrm{kN})$ & $F x 2(\mathrm{kN})$ & $F x 3(\mathrm{kN})$ \\
\hline 7.07 & -13.119 & -15.507 & -17.900 \\
15.52 & -13.193 & -15.592 & -17.990 \\
100 & -11.491 & -13.580 & -15.669 \\
\hline
\end{tabular}

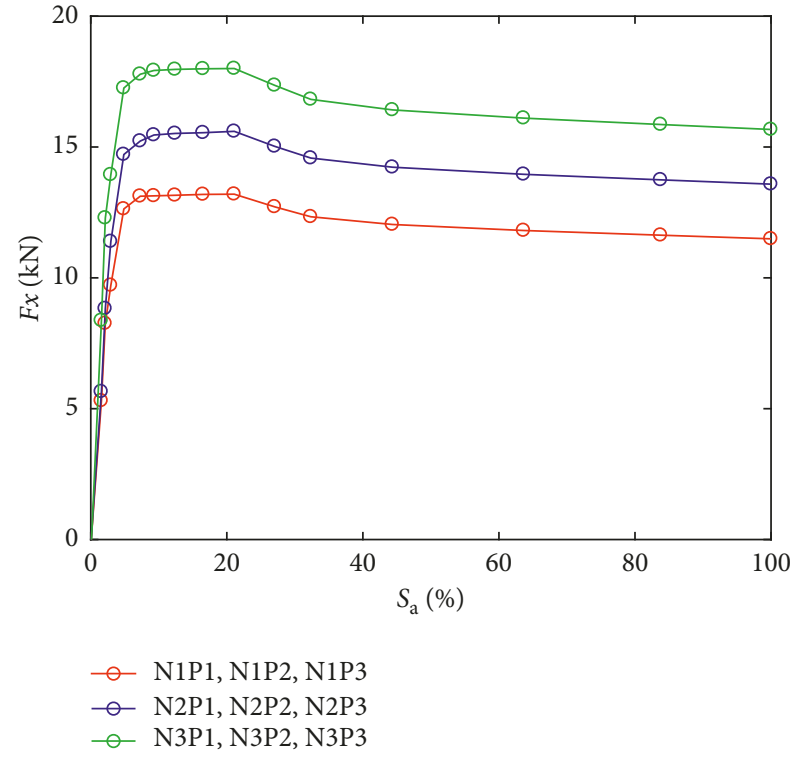

FIgURE 9: Longitudinal force on the tire at different slip ratios during acceleration.

TABLE 6: Longitudinal force on the tire at some typical slip ratios during acceleration.

\begin{tabular}{lccc}
\hline$S_{\mathrm{a}}(\%)$ & $F x 1(\mathrm{kN})$ & $F \times 2(\mathrm{kN})$ & $F \times 3(\mathrm{kN})$ \\
\hline 9.28 & 13.133 & 15.458 & 17.924 \\
21.09 & 13.197 & 15.598 & 17.999 \\
100 & 11.491 & 13.580 & 15.669 \\
\hline
\end{tabular}

longitudinal force of the tire reaches the maximum value. When the slip ratio is less than $21.09 \%$, the contact area between the tire and the ground will partially slip. When the slip ratio is greater than $21.09 \%$, the contact area between the tire and the ground is completely slippage. This is obviously different from the critical value of the slip ratio of the bus braking state.

In order to clearly and accurately find the critical slip ratios under different conditions, Table 6 is specifically formulated to show the longitudinal force on the tire at some typical slip ratios during acceleration. According to the change of longitudinal force, the acceleration state can be divided into three stages with three different slip ratios. When the slip ratio is less than $9.28 \%, F x$ is in the stage of rapid growth. In this stage, when the driving force of the engine appears, the tread at the rear of the tire which is about to contact the ground will be stretched and thus elongated. Fx increases with the increase of the rolling radius. When the slip ratio is more than $9.28 \%$ and less than $21.09 \%, F x$ is in the stage of slow growth. When the slip ratio is larger than $21.09 \%$ and less than $100 \%, F x$ decreases as the slip ratio increases; at this time, the tire is in a state of complete acceleration. Since complete acceleration is an unstable driving condition which may lead to sideslip or other dangerous situations of the whole vehicle, the slip ratio should be close to but not more than $21.09 \%$ in order to accelerate effectively and safely. 


\section{Conclusions}

In order to obtain the contact stress distribution of tirepavement under multiple working conditions and improve the handling stability and driving safety of the bus, the $3 \mathrm{D}$ dynamic simulation contact model is created to conduct a reliable analysis of tire-pavement stress and the critical slip ratio. Through this method and procedure, the following conclusions are determined.

First of all, the magnitudes, direction, and distribution of tire-pavement contact stresses are affected by multiple working conditions, and it is not a circular or rectangular uniformly distributed load.

Furthermore, slip ratio has significant impact on longitudinal force during the tire rolling phase. In the braking and acceleration conditions, as the slip ratio increases the resultant longitudinal force grows rapidly, then grows slowly, and finally remains constant. However, once the slip ratio is larger than the critical value of $15.52 \%$ and less than $100 \%$ in the braking condition, the bus could enter the state of complete braking, and the resultant longitudinal force decreases as the slip ratio increases.

In addition, once the slip ratio of acceleration is greater than the critical slip rate of $21.09 \%$ and less than $100 \%$, the bus may enter the state of complete acceleration. The critical slip ratio at the time of braking is smaller than that at the time of acceleration.

Finally, the state of complete braking and acceleration is a dangerous driving condition. Therefore, in order to brake and accelerate effectively and safely, and make full use of friction conditions, the braking slip ratio should be close to but not more than $15.52 \%$, and its acceleration slip ratio should be close to but not more than $21.09 \%$.

Tire-pavement contact stress is analyzed at multiple working conditions (free rolling, acceleration, and turning), and also the critical slip ratio is investigated in the braking and acceleration condition. This research is done from the aspect of tire inflation pressure, tire load, longitudinal translation speed of the tire, the angular velocity of the tire, and the longitudinal force. Conventional methods focus on the critical slip ratio of braking only, or setting the critical slip ratio and then observing the changes of longitudinal force. Our new approach takes more factors into considerations by investigating the changes of longitudinal force to pinpoint and compare the critical slip ratio during braking and acceleration to increase driver safety. This method can be used to improve operational stability and make full use of friction conditions. In the future research, heat transfer by tire-pavement contact and pavement features will be discussed.

\section{Data Availability}

The data used to support the findings of this study are included within the article.

\section{Conflicts of Interest}

The authors declare no conflicts of interest regarding the publication of this paper.

\section{Acknowledgments}

This work was supported by the 2018 National Major Scientific Research Instrument Development Project of China (No. 51827812), National Natural Science Foundation of China (Nos. 51778509 and 51578430), Natural Science Foundation of Hubei Province (No. 2018CFB293), and Resource Construction Project of Huanghuai University (No. 2018XJGLX0419).

\section{References}

[1] M. H. R. Ghoreishy, M. Malekzadeh, and H. Rahimi, “A parametric study on the steady state rolling behavior of a steelbelted radial tire," Iranian Polymer Journal, vol. 16, no. 8, pp. 539-548, 2007.

[2] M. A. Elseifi, I. L. Al-Qadi, P. J. Yoo, and I. Janajreh, "Quantification of pavement damage caused by dual and wide-base tires," Transportation Research Record: Journal of the Transportation Research Board, vol. 1940, no. 1, pp. 125135, 2005.

[3] I. L. Al-Qadi and P. J. Yoo, "Effect of surface tangential contact stress on flexible pavement response," Journal of the Association of Asphalt Paving Technologists, vol. 76, no. 8, pp. 663-692, 2007.

[4] H. Wang and I. L. Al-Qadi, "Evaluation of surface-related pavement damage due to tire braking," Road Materials and Pavement Design, vol. 11, no. 1, pp. 101-121, 2010.

[5] I. L. Al-Qadi, H. Wang, P. J. Yoo, and S. H. Dessouky, "Dynamic analysis and in-situ validation of perpetual pavement response to vehicular loading," Transportation Research Record: Journal of the Transportation Research Board, vol. 2087, no. 1, pp. 29-39, 2008.

[6] H. Wang, I. L. Al-Qadi, and I. Stanciulescu, "Simulation of tyre-pavement interaction for predicting contact stresses at static and various rolling conditions," International Journal of Pavement Engineering, vol. 13, no. 4, pp. 310-321, 2012.

[7] H. Wang, L. Imad, Al-Qadi, and I. Stanciulescu, "Effect of surface friction on tire-pavement contact stress during vehicle maneuvering," Journal of Engineering Mechanics, vol. 140, no. 4, article 04014001, 2014.

[8] P. Gruber and R. S. Sharp, "Shear forces in the contact patch of a braked-racing tyre," Vehicle System Dynamics, vol. 50, no. 12, pp. 1761-1778, 2012.

[9] P. Gruber, R. S. Sharp, and A. D. Crocombe, "Normal and shear forces in the contact patch of a braked racing tyre. Part 1: results from a finite-element model," Vehicle System Dynamics, vol. 50, no. 2, pp. 323-337, 2012.

[10] H. Zhou, G. Wang, Y. Ding, J. Yang, C. Liang, and J. Fu, "Effect of friction model and tire maneuvering on tirepavement contact stress," Advances in Materials Science and Engineering, vol. 2015, Article ID 632647, 11 pages, 2015.

[11] J. A. Hernandez and I. L. Al-Qadi, "Hyperelastic modeling of wide-base tire and prediction of its contact stresses," Journal of Engineering Mechanics, vol. 142, article 04015084, 2016.

[12] T. John, Tielking, and M. A. Abraham, "Measurement of truck tire footprint pressures," Transportation Research Record: Journal of the Transportation Research Board, vol. 35, no. 1435, pp. 92-99, 1994.

[13] M. De Beer, C. Fisher, and F. J. Jooste, "Determination of pneumatic tire pavement interface contact stresses under moving loads and some effects on pavements with thin asphalt surfacing layers," in Proceedings of the 8th International 
Conference on Asphalt Pavements, vol. 1, pp. 179-227, Seattle, WA, USA, August 1997.

[14] R. A. Douglas, W. D. H. Woodward, and A. R. Woodside, "Road contact stresses and forces under tires with low inflation pressure," Canadian Journal of Civil Engineering, vol. 27, no. 6, pp. 1248-1258, 2000.

[15] M. Pau, B. Leban, and A. Baldi, "Ultrasonic measurements of contact area and pressure distribution of a pneumatic tire on a rigid surface3," Tire Science and Technology, vol. 36, no. 1, pp. $43-62,2008$.

[16] B. Chen, X. Zhang, J. Yu, and Y. Wang, "Impact of contact stress distribution on skid resistance of asphalt pavements," Construction and Building Materials, vol. 133, pp. 330-339, 2017.

[17] M. Yu, G. Wu, L. Kong, and Y. Tang, "Tire-pavement friction characteristics with elastic properties of asphalt pavements," Applied Sciences, vol. 7, no. 11, p. 1123, 2017.

[18] I. L. Al-Qadi and H. Wang, "Prediction of tire pavement contact stresses and analysis of asphalt pavement responses: a decoupled approach," Journal of the Association of Asphalt Paving Technologists, vol. 80, pp. 289-316, 2011.

[19] J. P. Hambleton and A. Drescher, "Modeling wheel-induced rutting in soils: rolling," Journal of Terramechanics, vol. 46, no. 2, pp. 35-47, 2009.

[20] S. Kato, N. Sato, and T. Matsubayashi, "Some considerations on characteristics of static friction of machine tool slideway," Journal of Lubrication Technology, vol. 94, no. 3, pp. 234-247, 1972.

[21] J. T. Oden and J. A. C. Martins, "Models and computational methods for dynamic friction phenomena," Computer Methods in Applied Mechanics and Engineering, vol. 52, no. 1-3, pp. 527-634, 1985.

[22] M. G. Pottinger, "The three-dimensional contact patch stress field of solid and pneumatic tires," Tire Science and Technology, vol. 20, no. 1, pp. 3-32, 1992. 


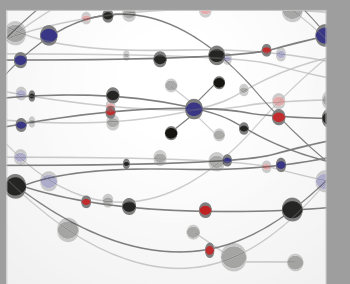

The Scientific World Journal
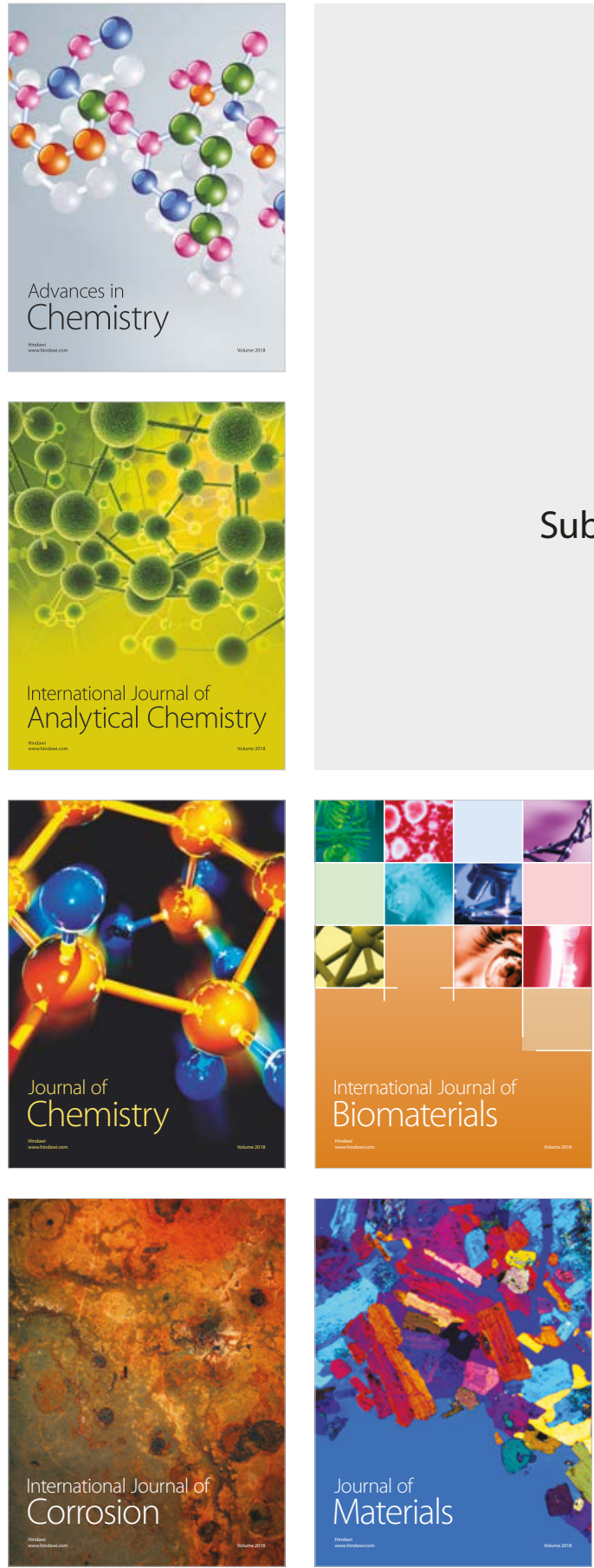

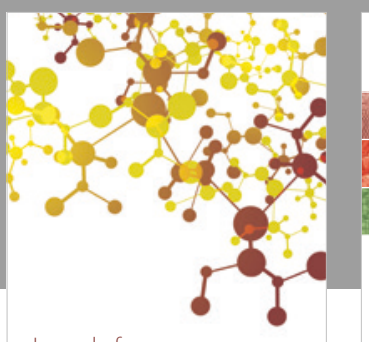

Journal of

Applied Chemistry
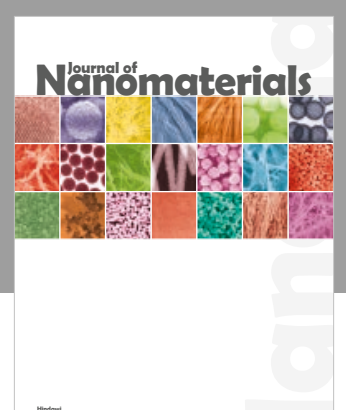

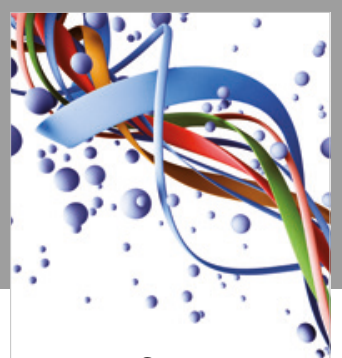

Scientifica

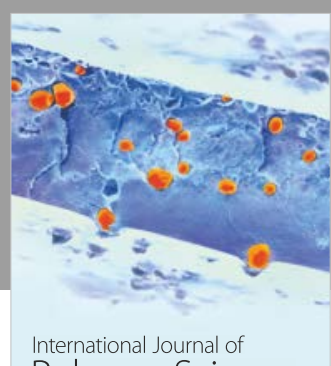

Polymer Science

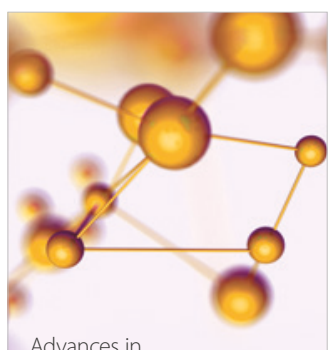

Physical Chemistry
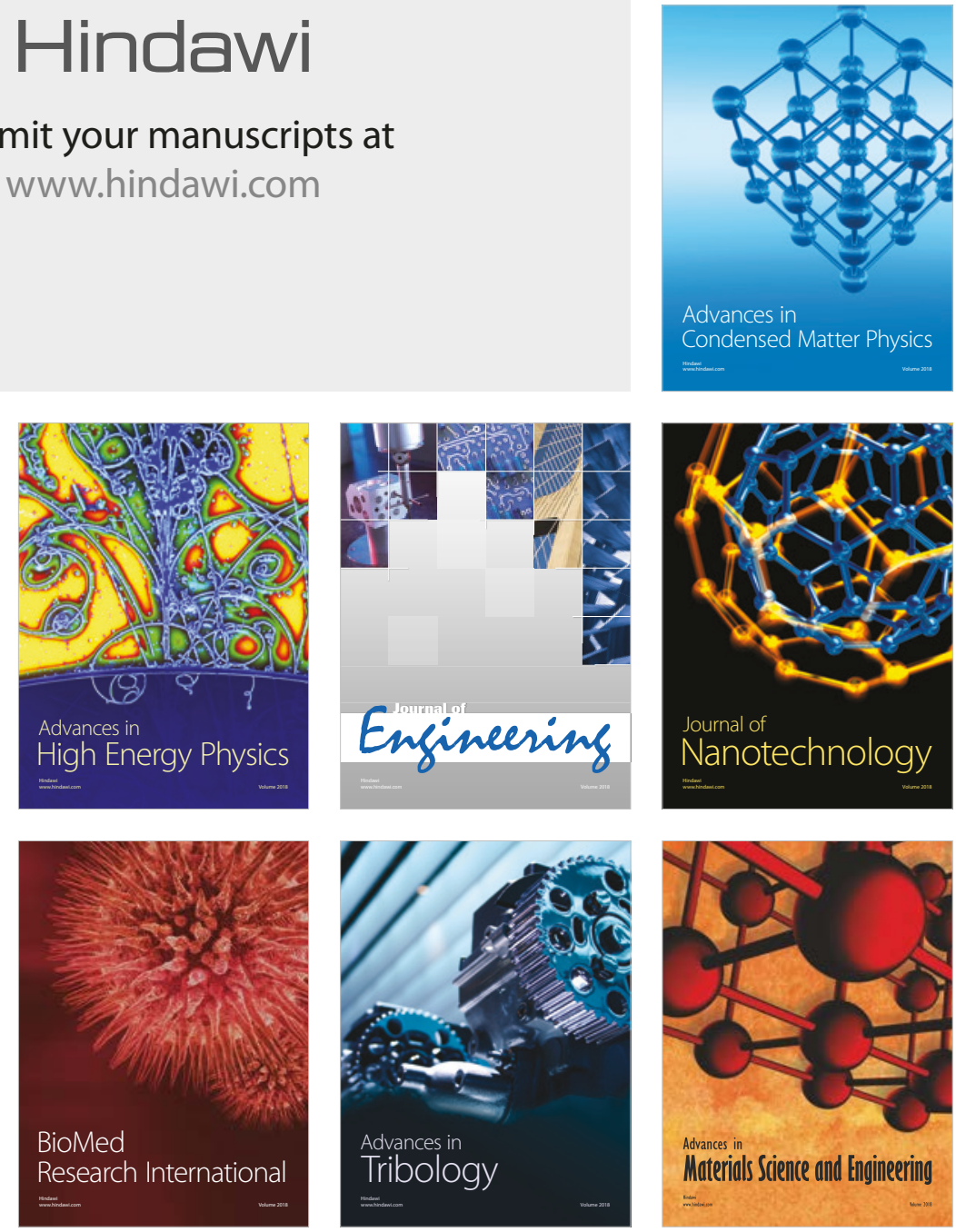